\title{
ROGELIA EN FINISTERRE. UN DRAMA DE ÁLVARO CUNQUEIRO $^{1}$
}

Ninfa Criado Martínez

Universidad de Sevilla

La producción teatral de Álvaro Cunqueiro no es extensa, se reduce a tres piezas completas: La noche va como un río, El incierto señor don Hamlet, príncipe de Dinamarca y Rogelia en Finisterre; y otras cuatros sin completar: Juan, el buen conspirador ${ }^{2}$, única escena escrita como prólogo para una tragedia; Palabras en la víspera, función en dos cuadros con un epílogo; Las escenas segunda y vigésimo quinta de la pieza de teatro chino llamada la dama que engañada por un diablo elegante quiso comprarle la perdiz que hablaba o la verdadera historia de un mandarín que por no gastar quedó cornudo y Función de Romeo y Julieta, famosos enamorados ${ }^{3}$.

El teatro es la faceta menos conocida de su literatura; como dramaturgo, ya lo hemos dicho en otra ocasión ${ }^{4}$, fue un escritor escasamente realizado, probablemente por el desencanto que le produjo no ver su obra representada. No obstante, su obra dramática posee el interés de quien, ya desde la década de los años veinte, se sumó al ansia de renovación de otros jóvenes dramaturgos. Realmente, cada una de sus piezas supone una búsqueda de nuevas formas de expresión teatral.

Rogelia en Finisterre es una acción dramática en siete cuadros, escrita en castellano, que no se llegó a estrenar. En 1941 apareció publicada por primera vez en el Suplemento literario de Vértice; durante muchos años ha permanecido arrinconada hasta que en 1991 la reeditaron María Camino Noia y Xesús Alonso Montero, formando parte del volumen Álvaro Cunqueiro. Escritos recuperados.

1 Álvaro Cunqueiro, El incierto señor Don Hamlet y otras piezas dramáticas (Teatro completo), Barcelona, Destino, 1992.

${ }^{2}$ Vid. Ninfa Criado, "Un prólogo para ser representado: Juan, el buen conspirador de Álvaro Cunqueiro", Voz y Letra (Revista de literatura), Tomo XII, Volumen 2, 2001, Arco/Libros, S.L. pp. 97-104.

${ }^{3}$ De los siete títulos tres son incluidos por el autor en el seno de sus novelas: La noche va como un rio presente en Un hombre que se parecía a Crestes; Función de Romeo y Julieta, famosos enamorados en Las crónicas del sochantre y Las escenas segunda y vigésimo quinta de la pieza de teatro chino llamada la dama que engañada por un diablo elegante quiso comprarle al viento la perdiz que hablaba o la verdadera historia de un mandarín que por no gastar quedó cornudo en Cuando el viejo Sinbad vuelva a las islas. Esta fórmula de instalar el teatro dentro del relato, la manera de enlazar las secuencias dramáticas con el nivel primero de la narración lo hemos estudiado en Álvaro Cunqueiro, El juego de la ficción dramática, CSIC, (en prensa).

${ }^{4}$ Incluyo una amplia contextualización del teatro de Cunqueiro en mi estudio "El discurso metateatral de Álvaro Cunqueiro (Análisis e interpretación de El incierto señor don Hamlet, príncipe de Dinamarca)", Analecta Malacitana, (en prensa).

${ }^{5}$ Álvaro Cunqueiro. Escritos recuperados, publicados por el Departamento de Filología Galega de la Universidad de Santiago de Compostela, Día das Letras Galegas, 17 de mayo de 1991. 
Rogelia en Finisterre es una pieza de perfecta representabilidad escénica, con un diálogo ágil y teatral, lleno de densidad poética. Obra insólita, diría Anxo Tarrío, "a caballo entre la maldición y la esperanza"6.

La acción transcurre en Finisterre. Durante mucho tiempo existió la creencia de que Finisterre era el fin del mundo conocido, de ahí su nombre. Cunqueiro conserva esta creencia para elevarla a la categoría de símbolo. Seis hombres viven en el Cabo, seres que subsisten al margen de toda palpitación humana. Como dice Rogelia, la protagonista, "cinco hombres vencidos, a quien está dedicada la muerte"7. En Finisterre no hay mujeres, Manuel, el más viejo, estuvo casado y Antonio recuerda a su madre; sobre ellos, se desconoce el motivo, ha caído una extraña maldición, no podrán tener descendencia porque la mujer que tenga hijos de ellos morirá. Todos aceptan esta condena, guiados por una fe en una futura Redención; a la espera de ella, Finisterre es un lugar inmóvil fuera del tiempo y al margen de la vida.

La falta de concreción temporal en la obra, se ignora la época en la que transcurre los hechos, remite al inmovilismo y enclaustramiento en el que permanece Finisterre; se orienta hacia el mensaje verbal y, al mismo tiempo, es expresión de la concepción dramática a la que se adhiere el autor, alejada del realismo. A esta imprecisión referencial se suma la ausencia de indicadores que informen acerca del tiempo transcurrido desde el comienzo de la obra hasta su desenlace. No faltan, sin embargo, algunas referencias verbales indirectas en las réplicas de los personajes y en las acotaciones a los diferentes momentos del día: mañana, tarde y noche, que marcan un tempo rápido:

-ANTONIO.- (...) Y ahora pasean al sol ${ }^{8}$.

-(Por la mañana aún luz de amanecida $)^{9}$.

-JUAN.- ¡Oh, Rogelia! ¡Buenos días, madrugadora Rogelia! ${ }^{10}$.

-JUAN.- ¡Buenas tardes! ${ }^{11}$.

-(En el campo. Noche. Cuatro escenarios...) $)^{12}$.

Estas referencias no aluden, como cabría esperar, a la mañana, a la tarde y a la noche de un mismo día. El desarrollo del conflicto requiere que entre estos indicadores imprecisos quede un mayor espacio latente de tiempo.

La elección de Finisterre para ubicar espacialmente el drama no responde a principios

6 Anxo Tarrío Varela, "Presentación", Alvaro Cunqueiro. Escritos recuperados, op. cit., p. 8.

${ }^{7}$ El incierto señor..., op. cit, p. 238.

${ }^{8}$ El incierto señor..., op. cit., p. 232.

${ }^{9}$ El incierto señor..., op. cit., p. 234.

${ }^{10}$ El incierto señor...,op. cit., p. 237.

${ }^{11}$ El incierto señor..., op. cit., p. 244.

${ }^{12}$ El incierto señor..., op. cit., p. 257. 
realistas. El Cabo es una edificación poética, que si bien no coincide físicamente con los espacios descritos en otros dramas de Cunqueiro ${ }^{13}$, si se asemeja conceptualmente a estos. En todos los casos tienen el mismo significado simbólico: son signos de la atmósfera reinante en el lugar, de la situación vital en la que los personajes se encuentran. Crean la sugestión de enclaustramiento y ahondan en la situación antitética entre el conflicto interno de los personajes -su realidad, su tiempo, su espacio- y el deseo, siempre proyectado hacia el exterior:

JUAN.-Finisterre, cabo del mundo, donde no hay mundo, demonio ni carne, pero donde había hambre, hambre negra, incubada en los huesos, macerada a pechos de hombre, agobiadora en la garganta, seca en lo más seco de las entrañas para que no hubiera agua bastante para tanta sed $^{14}$.

Rogelia en Finisterre es un drama pobre en acciones que se centra en la escenificación del conflicto interno de los personajes ${ }^{15}$, como es frecuente en los dramas segmentados en cuadros, si bien en este caso se trata de cuadros subordinados y no segmentados en bloques. Tras cada cuadro desciende el telón. La bajada del telón al final de los cuadros probablemente esté en función de ocultar al público los cambios de decorados, y por consiguiente del grado de ilusión que el autor quiera mantener. En este sentido, podemos decir que Rogelia en Finisterre constituye una excepción en la producción dramática de Cunqueiro, por cuanto no se advierte intento alguno por romper la ilusión escénica.

El primer cuadro es de carácter situacional; dos personajes informan al público acerca de las circunstancias en que viven los hombres que habitan Finisterre, de esta manera los espectadores están en disposición de comprender el conflicto. Don Agustín, el alcalde, representa la autoridad política y religiosa, es la fuerza represora que con criterios sociales, morales y religiosos trata de impedir que se alteren las costumbres. Don Agustín es el encargado de adelantar premonitoriamente el conflicto dramático que se quiere contar al público: en las costas de Finisterre ha naufragado un barco, sólo un pasajero salva la vida, los hombres encuentran en la playa a Rogelia, la cuidan y acuden a Don Agustín para que la inscriba en el libro de registros mientras se recupera. La llegada de esta mujer desencadena el conflicto: Rogelia será, advierte el alcalde, una fuente de discordia, la tentación en forma de mujer:

DON AGUSTÍN-. (...) Ibais a morir en paz y la tempestad os manda mujer. ¿No os basta saber que moriréis? Necesitáis ahora una mujer, esa mujer. Y tendréis hambre y discordia. Y os conoceréis el deseo en los ojos. (...) Ya escucharé desde mi cama cómo os aporreáis con los cuernos ${ }^{16}$.

Tras la exposición, en la parte central, la más amplia (cuadros $2^{\circ}, 3^{\circ}, 4^{\circ}, 5^{\circ}$ y $6^{\circ}$ ) se

\footnotetext{
${ }^{13}$ Una torre albarrana en Palabras en la víspera; la torre real de Elsinor en El incierto señor don Hamlet, príncipe de Dinamarca; la torre del Paso de Valverde en La noche va como un río.

${ }^{14}$ El incierto señor..., op. cit., pp. 246-247.

${ }^{15}$ Lo mismo cabe decir de La noche va como un río, El incierto señor don Hamlet, príncipe de Dinamarca y

Palabras en la víspera.
}

${ }^{16}$ Ibídem, p. 228. 
exhiben las interacciones que Rogelia mantiene con las cinco figuras masculinas del drama. Las complicidades de Rogelia con cada uno de los hombres que habita Finisterre resultan positivas; sirven para revelar las facetas ocultas de su personalidad y mostrar los contrastes temperamentales. En cambio, la presencia de Rogelia produce efectos negativos sobre la comunidad. Frente al unívoco grupo masculino, Rogelia es el carácter discrepante que rompe el aparente equilibrio inicial del Cabo.

El personaje de Juan es el primero en el que entran en conflicto dos series de fuerzas: el principio de libertad y el respeto a la autoridad; es consciente de que sus vidas se rigen según unos valores impuestos:

JUAN-. (...) Lanzado entre vosotros, porque mi padre aceptó una herencia, me aburro. Las maldiciones son muy aburridas. Espero que moriré joven, porque si llego a anciano, como Manuel, me moriré de hambre... ${ }^{17}$.

La presencia de Rogelia anima el deseo de vida durante tanto tiempo reprimido en los hombres; todos aceptan su condena -de la misma manera que las cinco hijas de Bernarda acatan su autoridad- hasta que la inevitable omnipresencia de Pepe el Romano, en este caso de Rogelia, desata las hambres, las tormentas silenciosas. El amor está presente en el drama sólo en cuanto sexo; Juan es el único capaz de comprender que la sexualidad contenida en nombre de la fe es una negación de la individualidad, una amputación del ser.

Para Juan el único acto de fe posible es Rogelia, y así lo expresa en palabras que tienen reminiscencias del amor cortés, del famoso monólogo de Calixto:

JUAN.- Creo en ti y en tus palabras; creo a punta de alba, a hora de mediodía, a velaluces, a la luna y a la estrella. ¡Rogelia! La verdad ahora en tus oídos antes de que vaya a tus labios: ni salvación ni condena importan (...) No me importa mi alma, Rogelia, sino mi hambre. ¡Adoro, adoro en ti todos mis años perdidos! ¡Cuánto bien me haces! $!^{18}$.

Una vez desafiada la autoridad, rotas las cadenas, Juan abandona a Rogelia y el Finisterre huyendo por el mar. La mujer, como hemos dicho, es la tentación, pero sobre todo la madre redentora, "María"19 la llamará Juan: "A cada uno dio lo que más falta le hacía" 20 . Su misión es enseñar a los hombres que tienen hambre, que el hambre se puede saciar, y para ello usa "como cebo los manjares más gratos"21, los del cuerpo, los de la lujuria. Rogelia no puede salvar por la vía del amor porque ella no es el puerto, es el faro que alumbra el camino para salir de las tinieblas, para recuperar la opción de ser hombre, la voluntad de ser:

JUAN.- (...) Y me voy de la tierra, me voy al mundo, a perderme, con ella o sin ella, porque lo que ahora tengo es hambre, un hambre, y mañana tendré otra y otra más. Nació vuestra religión y vuestro sacrificio para cambiar hombres y lo que cambiáis son hambres, hambres

\footnotetext{
${ }^{17}$ Ibídem, p. 235.

${ }^{18}$ Ibídem, p. 239.

${ }^{19}$ Ibídem, p. 242.

${ }^{20}$ Ibídem, p. 255.

${ }^{21}$ Ibídem, pp. 255-256.
} 
negras.(...) Finisterre, cabo del mundo, donde no hay mundo, demonio ni carne, pero donde había hambre, hambre negra, incubada en los huesos, macerada a pechos de hombre... ${ }^{22}$.

Rogelia sólo logrará redimir a Juan. El resto de los habitantes de Finisterre no podrá escapar a las consecuencias de su fe; los individuos son vencidos por el orden, la tradición y la autoridad. Tienen dos opciones y la elección de cualquiera de las dos les resultará dolorosa; por el tiempo del amor, del deseo, el del hombre, en definitiva, que les entrega Rogelia, deberán pagar un alto precio: condenarán fatalmente sus almas. Si deciden no violar las leyes divinas y sociales renunciarán a la vida. Todo lo que logran es aceptar que la carne es débil: "Barro somos y no hay más"23. No compartimos, pues, la interpretación de M. C. Ríos Panisse: "Só por mor dela se realizan na súa condición humana Juan, Gabriel e Antonio. Nunha palabra, co amor de Rogelia estes personaxes viven e disfrutan do vivir"24. Salvo en Juan, el concepto de culpa no desaparece jamás de sus conciencias:

JUAN.- Ellos creen que si te aman se condenan, pierden sus almas. Yo creo que si te amo me salvo. Te ofrezco, pues, infinitamente menos. Ellos tienen un alma que perder. Yo no puedo perderla porque no creo en su estúpida fe. Los odio... 25.

Gabriel es el más joven, el más puro. Fue concebido para anunciar, como su nombre indica, la Buena Nueva, para pronunciar en el momento de sus muertes un "Ave María". Pero Gabriel tampoco puede con su verdad, con su hambre, pierde la mocedad en brazos de Rogelia, y con ello su poder anunciador. Gabriel era necesario para la salvación del grupo; Rogelia, una vez más, ejercerá de María, madre redentora; Manuel y Antonio le piden que alumbre a un hijo a quien pondrán por nombre Gabriel. Un hijo que los "entierre a todos"26, a quien mantendrán "firme en la fe"27, que salve al hombre y los redima de sus pecados. Rogelia acepta, aún cuando sabe que para salvar las almas de los hombres es necesario sacrificar al hijo a la soledad de un espacio atroz, a ser sepultado en vida. A cambio de su supremo sacrificio exige ser amada y reconocida en su papel de redentora:

ROGELIA.- (...) ¡Mi castidad! Ya sé que crees que no existe, que piensas que cien agujas me carcomen, que soy del vicio y en él me anego. ¡Cómo te equivocas! Yo nací para compañera del hombre, de un hombre y no sé repartirme. Has de aceptarme tal y como soy, si no no seré madre de tu hijo. O hombre mío o tendrás que contar tu amor por noches, como Juan, como Gabriel....

\footnotetext{
${ }^{22}$ Ibídem, p. 246.

${ }^{23}$ Ibídem, p. 245.
}

${ }^{24}$ M.C. Ríos Panisse, "Inicios teatrais de Cunqueiro (1933-1941)", Boletín Galego de Literatura, Monografías, $\mathrm{n}^{\circ}$ 1, Álvaro Cunqueiro, Universidad de Santiago de Compostela, 1992, p. 127.

${ }^{25}$ El incierto señor..., op. cit., p. 239.

${ }^{26}$ Ibídem, p. 251.

${ }^{27}$ Ibídem, p. 251.

${ }^{28}$ Ibídem, p. 252. 
Se resuelve la obra rápidamente en el cuadro $7^{\circ}$ sin ofrecer una solución definitiva al conflicto planteado: Rogelia embarazada, Gabriel y Antonio empeñados en contagiar y ensuciar con su fanatismo al nuevo ser. Final abierto, pues, que concluye con la proclamación de una sentencia, la de Rogelia reclamando para su hijo el glorioso y monumental trabajo de ser por encima de todo un hombre:

ROGELIA.- Y si Juan regresa, mi victoria aún es más segura, porque borrará de su pecho toda fe. Que sufran y aguanten, sin más, su condición de hombre. Ya sé que no es fácil, que muchos mueren, que mil y mil caen. ¡Quiera Dios, una y cien veces, que mi hijo caiga! ${ }^{29}$.

Rogelia en Finisterre, ya lo hemos dicho, es una pieza insólita. Los lectores familiarizados con la obra de Cunqueiro echamos en falta muchos de los motivos redundantes que fácilmente identificamos en sus textos; posiblemente, es la única de sus creaciones que no se organiza alrededor de un material artístico y cultural preexistente ${ }^{30}$. No se acusa en ella el fenómeno de teatro consciente de ser teatro, adolece de las teorías teatrales que todas sus obras muestran en mayor o menor medida, la presencia del dramaturgo no se percibe. De entre todas sus obras es la que más se acerca a las promociones inconformistas del teatro español tras la Guerra Civil. La obra sin ser realista no hay que perder de vista que es un drama simbólico- es una clara denuncia contra la hipocresía moral y el fanatismo religioso. Su crítica probablemente va dirigida a la sociedad española de la época, estricta e intolerante, si bien el conflicto entre el individuo y la sociedad es un trance universal. Su honda simbología bíblica: Pedro el pescador, Gabriel, el ángel que anuncia la Buena Nueva, Rogelia María Magdalena y María, madre redentora, el hijo sacrificado para salvar a la humanidad, sirven al autor para exponer su temática en torno al anhelo de realización humana y a las dolorosas trabas represoras.

Por otra parte, Rogelia en Finisterre nos recuerda algunos de los dramas de Ramón Gómez de la Serna; especialmente aquellos que tienen como tema la necesidad de reconocer la primordial importancia del instinto sexual en la total realización del ser humano. En torno a este tema estructura Gómez de la Serna El drama del palacio deshabitado. Asimismo, la función liberadora de Rogelia también parece tener que ver con la defensa feminista de Gómez de la Serna en Beatriz, Desolación y El laberinto. Para el autor de las Gregerías la mujer sexualmente independiente está en mejor condición de alcanzar la liberación. El sexo es analizado en las piezas de Cunqueiro como elemento transgresor y como experiencia individual del alma humana. Ante este sentimiento hombres y mujeres se comportan de manera diferente: frente al hombre que se muestra vacilante ${ }^{31}$, la mujer no oculta sus deseos, es sexualmente activa, representa el comportamiento libre del ser humano que elige su vida y asume las consecuencias de su elección ${ }^{32}$ :

\footnotetext{
${ }^{29}$ Ibídem, pp. 258-259.

${ }^{30}$ Ulises, Sinbad, Orestes, Hamlet, Merlín, doña Inés, doña Urraca...son los protagonistas de sus obras. Como puede comprobarse, su imaginación parte de los personajes de la cultura, a quienes recrea hasta otorgarles una imagen propia. No ocurre así en Rogelia en Finisterre, si bien la función de algunos personajes aluden de forma simbólica, como veremos más tarde, a ciertas figuras del evangelio.

${ }^{31}$ Vease el comportamiento del grupo de protagonistas masculinos de Rogelia en Finisterre; el príncipe Hamlet en El incierto señor don Hamlet, príncipe de Dinamarca y el rey Alfonso en Palabras en la víspera.
} 
GERDA.-Porque quiero que sepan que fui yo quien elegí, Polonio...Y porque fui yo quien elegí, pagué, pago. ${ }^{33}$

URRACA.-...¿Tú, si compras alguna cosa, pagas?

BELVÍS.- ¡Así es mi señora!

URRACA.- ¿Y cuanto más rica la cosa, más precio?

BELVÍS.-¡Así es! ${ }^{34}$

La acción de Rogelia en Finisterre tiene lugar en cuatro decorados distintos: despacho de don Agustín, habitación de Juan, almacén y campo. El paso de un cuadro a otro supone en todos los casos un cambio de decorado, salvo en los cuadros segundo y tercero que mantienen el mismo. Sobre ello volveremos más tarde. No reproduce Cunqueiro una realidad detallada, con datos precisos. Es un decorado estilizado y orientativo que, como signo, remite a las funciones prácticas, a las actividades que en él y con él los personajes pueden realizar. La elección del decorado, sin embargo, no responde a principios realistas, porque por encima de las funciones prácticas que de él se deducen, crea una atmósfera en consonancia con el conflicto del drama o, lo que es lo mismo, una relación entre espacio y conflicto. En su función primaria estos objetos remiten a la actividad laboral ejercida por los personajes:

-(Despacho de Don Agustín. Cajas de conserva, tabales de salazón, sacos. Colgados del techo, zuecos y botas de agua) ${ }^{35}$.

-(Antonio se sentó en el suelo y hace nudos en su cuerda de aparejo $)^{36}$.

-(El almacén: sacos, redes, una lancha acabrada, un arado $)^{37}$.

-(Están trenzando cuerdas y anasádolas $)^{38}$.

Pero el hecho de que los espacios estén desprovistos de cualquier objeto personal es significativo: los carga de valor semántico con respecto a los sujetos; es decir, actúan como signos de la situación vital en la que los personajes se encuentran. Ya dijimos que Finisterre

${ }^{32}$ El protagonismo de la mujer y del tema sexual en el teatro de Cunqueiro contrasta con la casi total ausencia de los mismos en su narrativa.

${ }^{33}$ El incierto señor..., op.cit., p. 72

${ }^{34}$ El incierto señor..., op. cit.,179. Gerda y Urraca son respectivamente las protagonistas femeninas de El incierto señor don Hamlet, príncipe de Dinamarca y Palabras en la víspera.

${ }^{35}$ El incierto señor..., op. cit., p. 227.

${ }^{36}$ El incierto señor..., op. cit., p. 235.

${ }^{37}$ El incierto señor..., op. cit., p. 243.

${ }^{38}$ El incierto señor..., op. cit., p. 243. 
es una edificación literaria por encima del realismo, en la que cinco hombres viven al margen de la vida. El escenario, por esta razón, se estiliza simbólicamente; la ausencia de calor y color da a entender la única actividad que a estos individuos les está permitida: el trabajo, en él se realizan y en él alcanzan su salvación:

ANTONIO.- Aprenderás a tratarla [la tierra], a darle y a pedirle. Te consolarás con ella y te sentirás reconfortado cuando te levantes, después de dormir la siesta sobre ella. Los caminos del ganado los sabes y las voces también. Pastorearás. Y así aguantarás la vida y tu condición de hombre. (...) Entre el mar y la tierra buscarás la compañía que no habrán de darte mujer e hijos, que no puedes tener... ${ }^{39}$.

En la descripción del cuarto de Juan se menciona con insistencia una ventana que se abre al mar. En la primera acotación de la Escena I del Cuadro Segundo se alude a lo que ocurre fuera del espacio escénico y que el espectador no podrá ver, a no ser que el director de escena considere el valor simbólico de su presencia: "(Juan en la ventana, siguiendo la salida de una barca)". El mar y la barca son un estímulo visual, que le permiten a Juan expresar en palabras las grandes verdades que estos hombres sólo pueden decirse en el silencio de sus vidas. El autor considera necesario ayudarse de signos verbales para definir el sentido de este signo visual que tal vez algunos espectadores no estén en disposición de interpretar:"Aboina ahora... Ya leva...Ya está fuera y libre: dos palabras, nada más que dos palabras. ¡Fuera y libre!"40. Nada de lo que hay en el interior de la habitación de Juan interesa al espectador, porque nada despierta el apego ni el interés del protagonista; sigue con el curso de la mirada el camino emprendido por la barca, el que desearía con todas sus fuerzas poder iniciar para abandonar y escapar de Finisterre, un lugar que sólo encuentra salida por el mar.

Ya dijimos que el paso de un cuadro a otro supone, en todos los casos, un cambio de decorado salvo en el tránsito del segundo al tercero, en los que se mantiene la habitación de Juan con una pequeña pero significativa variación:"Habitación de Juan. Hay flores en la $m e s a " 41$. Añadir el detalle floral al decorado está en relación con el desarrollo del drama, en el que se ha producido una primera alteración sobre las posiciones iniciales. El efecto que ejerce Rogelia sobre Juan se traduce en este objeto del decorado. Una vez más, en un procedimiento semejante al anterior, Rogelia explica con signos verbales el significado de este signo:

¿Ve usted esas flores? He ido a buscarlas a la Corona. Cuando Juan llegue encontrará la puerta abierta, la ventana abierta, mis brazos abiertos ${ }^{42}$.

Cunqueiro acude a la información de la palabra para dejar bien claro que todas las realidades de su escena representan otras realidades, signos que alcanzan su codificación sobre la escena. El decorado es un elemento creador de significado que como auténtico tropo visual hay que interpretar. Por otra parte, el que los signos -bien sean orales o

\footnotetext{
${ }^{39}$ Ibídem, pp. 243-244.

${ }^{40}$ Ibídem, p. 234.

${ }^{41}$ El incierto señor..., op. cit., p. 240.

${ }^{42}$ Ibídem, p. 241.
} 
visuales- no aparezcan aislados viene a confirmar una vez más que los signos teatrales siempre están en relación con su contexto semiótico, o sea, en relación con los otros signos de la escena.

Las acotaciones también informan, de forma escueta, de los signos del grupo de los kinésicos, los proxémicos, mímicos y gestuales. En cambio renuncia el autor a informar acerca de los signos de la apariencia externa de los personajes ${ }^{43}$. Este déficit podría interpretarse como la manifestación de confianza que el autor deposita en los directores; o simplemente como que el autor quiere ignorar las posibilidades significativas de estos signos. Ya dijimos que Rogelia en Finisterre no es un teatro de acciones sino de caracteres que se concentra en el conflicto interno de los personajes. Los receptores acceden a los rasgos psíquicos, a la identidad de éstos, por los actos de habla, por lo que los personajes hacen o dicen. Precisamente que se les prive de las posibilidades expresivas del aspecto externo, puede interpretarse como una renuncia deliberada a la que hay que asignarle un valor semántico. Desde nuestro punto de vista, éste es el mismo que el teatro del Barroco desarrolló sobre el mundo visible, siempre sujeto a los engaños de la apariencia externa. La verdadera realidad permanece inaccesible a los sentidos. Creemos que este es el motivo por el que Cunqueiro para la presentación de la figura dramática renunció a las posibilidades significativas del aspecto externo.

Pese a lo expuesto, es necesario reconocer el predominio de lo verbal en esta pieza, así como en todo el teatro de Cunqueiro. Todos los personajes hacen abundante uso en sus réplicas de la retórica, especialmente de los tropos; en consecuencia las palabras, las frases de cada parlamento van cargadas de dobles sentidos. El autor siempre se mantuvo fiel a los principios dramáticos que valoran la elaboración artística del discurso. Por esta razón, por encima de la adecuación del lenguaje a las figuras, a Cunqueiro le preocupa la unidad estilística del drama.

${ }^{43}$ Cunqueiro apenas esboza en su teatro el aspecto externo de los nersonaies. 
